\section{Burning conditions}

\author{
D.B. Spalding
}

The Mathematical Theory of Combustion and Explosions. By Ya. B. Zeldovich, G.I. Barenblatt, V.B. Librovich and G.M. Makhviladze. Consultants Bureau (Plenum): 1985. Pp.597. \$95, £90.25.

IN ESSENCE, the mathematical theory of combustion is simple: molecules interact, and are created or destroyed, as a consequence of the reactions studied by chemical kineticists; these sources and sinks give rise to concentration and temperature gradients which engender diffusional fluxes, of the kind represented by the laws of Fick and Fourier; simultaneously, either because of the density changes or of conditions imposed at the boundaries, the products and reactants are set in motion in a manner governed by the Navier-Stokes equations; the high temperatures give rise to radiative transport of energy in accordance with the classical laws; and the interchanges of mass, momentum and energy with the surroundings can also be expressed quantitatively.

A given combustion phenomenon can therefore be represented by an established set of simultaneous partial differential equations, complicated by the fact that many of the included variables (for example density, concentrations, temperature) are linked by known algebraic relations expressing the nature of the materials in question. Once the initial and boundary conditions have been fully worked out, the problem in question is then ready for solution.

Of course, the non-linearity of the equations, and the multi-material, multidimensional character of most combustion phenomena, demand the use of numerical methods and of powerful digital computers. A consequent danger is that the employment of such formidable apparatus will so distract and overburden the theorist that he fails to achieve that perception of interrelationships, and ability to anticipate outcomes, which we call "understanding".

Any combustion specialist who wishes to strengthen his understanding will do well to study the present book. Soviet scientists have done much of the pioneering research on this subject, particularly in the formulation of concepts and provision of explanations of major phenomena. The senior author has been especially prominent (with Semenov, Frank-Kamenetskii, Shchelkin, Vulis and others) while his co-authors too have themselves made notable contributions.

That pioneering work was performed before electronic digital computers were available, for which reason the mathematical formulations had to be simplified; but it was conducted with realism and intelligence, and without extremism. Just enough of the physics was retained (and especially the steep temperature dependences which give rise to nonlinearity) for the important phenomena of ignition, propagation, instability and extinction to be understood; and simple approximate methods of solution were devised for the resulting equations

The book retains many of the virtues of the early works. But although it pays some attention to more recent trends and preoccupations, it does not follow them very far. The reader will therefore find little about theories of turbulent combustion; and recent advances in large-scale computer simulations of flames are not mentioned.

The original Russian edition of the book appeared in 1980. Its lucidity has been well preserved in the English translation and it can be read with both pleasure and advantage by combustion scientists in the Western world, several of whom will find that ideas which they have attributed to themselves or their contemporaries were already thoroughly understood a generation ago. The authors have, incidentally, addressed a graceful preface to their Western readers, while their introduction, which is the same as that of the Russian edition, reveals their full awareness that combustion is a truly international science.

D. B. Spalding is Professor of Heat Transfer in the Computational Fluid Dynamics Unit, Impe rial College, Exhibition Road, London SW7 $2 B X, U K$

\section{Fit for survival}

\section{John Hearn}

Reproduction in Mammals, 2nd Edn. Book 4, Reproductive Fitness. Edited by C.R. Austin and R.V. Short. Cambridge University Press: 1985. Pp.241. Hbk $£ 22.50, \$ 39.50 ; p b k £ 8.95, \$ 14.95$.

THE success or failure of reproduction is crucial to survival or extinction, and thus of immense evolutionary importance. Knowledge of the process is also of great consequence in the management and conservation of species diversity in an ever more crowded world. This will continue to be a central question during the next 50 years, over which the world's human population will double to nearly nine thousand million. Much of the increase will take place in developing countries that now provide the remaining homelands of many exotic species.

Our current understanding of reproductive strategies, species variations, the genetic, behavioural and immunological factors in reproductive fitness, and the influence of senescence, is well presented in this volume, the updated version of Book 4 of the first edition of Reproduction in
Mammals (published in 1972 under the title Reproductive Patterns). It is virtually a different book: two authors of the original complement remain and there are now seven chapters instead of five. All of the contributions are valuable, but among the newcomers I particularly enjoyed the chapters on genetics (Roger Land), environment (Brian Follett) and reproductive strategies (May and Rubenstein). Revision of the series as a whole continues next year with the appearance of the fifth volume, to be entitled Manipulating $\mathrm{Re}$ production.

While we are rapidly improving our appreciation of general principles, we are still desperately ignorant of precise details of the basic factors that limit survival of individual species. Among mammals alone we have an adequate understanding of fewer than 50 of the 4,000 species, including those on which our agriculture and biomedical sciences are based, and our domestic pets. It is ironic that this knowledge has contributed enormously to the success of our own species in helping us to overcome all natural environmental constraints, but in consequence threatens the survival of most other species. There is a pressing need to define the essential requirements of key species, so that conservation and management policies for the shrinking wildernesses genuinely meet the needs of these species and of others that share the same territory. A hard, quantifiable, scientific approach, at the fundamental level achieved in this book, is critical for the future of animals, including man.

To quote from Roger Short's contribution (Chapter 2, on species differences):

Readers ... will have been struck by the enormous diversity of reproductive mechanisms across mammalian species. About the only common factor is that, somewhere along the line, a spermatozoon meets an egg and so a new individual is formed. Everything else is subject to enormous variability, so that generalisations become impossible. This may act as a deterrent to the faint hearted, who are baffled by complexity; in reality it should be seen as an exciting challenge, encouraging us to probe deeper for the reasons underlying the diversity.

The strength of this book, and of the series of which it is part, is that a bewildering complexity and variability of species, physiological mechanisms and scientific disciplines is made readable, understandable and exciting. The contents are right up to date and point the way to further research development. While the book is aimed primarily at an undergraduate audience, research workers and lecturers will also find it invaluable. As a definitive text in a fast-moving field, I commend it as required reading for those interested in reproductive biology

Tohn Hearn is Visiting Professor in Zoology at University College London, and Director of Science of the Zoological Society of London, Regent's Park, London NW1 4RY, UK 